\title{
HISTÓRIAS, TRAJETÓRIAS E INSUBORDINAÇÃO CRIATIVA
}

\author{
STORIES, TRAJECTORIES AND CREATIVE INSUBORDINATION
}

\author{
Antonio Carlos de Souza \\ Universidade Estadual Paulista (UNESP), Campus de Guaratinguetá \\ toncaza@gmail.com \\ Daiane Silva Assunção \\ Universidade Estadual Paulista (UNESP), Campus de Guaratinguetá \\ day silva1991@yahoo.com.br
}

\section{Resumo}

Ousar é dar asas às suas convicções, é buscar respostas ao que não entende, é enfrentar o que lhe causa estranhamento. É se permitir e ir em frente. Este artigo surgiu das reflexões de um educador matemático sobre parte de sua trajetória profissional. Apresenta o início de sua carreira docente, marcada por episódios de insubordinação criativa, chegando à sua atuação no ensino superior onde sua trajetória se cruza com a trajetória de uma de suas alunas que, mesmo estando em um curso de formação de professores de Matemática, aceitou o desafio de participar de um projeto envolvendo um grupo de crianças da Educação Infantil. O projeto teve como contexto a literatura infantil e a partir das histórias contadas para as crianças foram abordadas algumas ideias matemáticas e estatísticas.

Palavras-chave: Subversão responsável; Educação Infantil; Educação Matemática; Educação Estatística.

\begin{abstract}
To dare is to give wings to your convictions, to seek answers to what you do not understand, is to face what causes you estrangement. It is to allow and to go forward. This article arose from the reflections of a mathematical educator on part of his professional trajectory. Presents the beginning of his teaching career, marked by episodes of creative insubordination, arriving at his performance in higher education where his trajectory crosses with the trajectory of one of his students who, even being in a training course for mathematics teachers, accepted the challenge of participating in a project involving a group of children in Early Childhood Education. The project had as context the children's literature and from the stories told to the children were approached some mathematical ideas and statistics.
\end{abstract}

Keywords: Responsible subversion; Early Childhood Education; Mathematical Education; Statistical Education. 


\section{Para início de conversa}

As ideias para escrever este texto surgiram pela participação, de seus autores, na $1^{\text {st }}$ International Conference on Creative Insubordination in Mathematics Education, realizada nos primeiros dias de agosto de 2017. Inicialmente, ao evento, foi submetido o trabalho intitulado "Contando histórias e construindo gráficos: a insubordinação criativa na Educação Infantil" cujo objetivo foi apresentar um recorte de um projeto desenvolvido a partir de uma parceria entre a Universidade Estadual Paulista, Campus de Guaratinguetá e uma escola pública municipal, situada na mesma cidade.

Os participantes foram um professor da universidade (coordenador do projeto) e uma aluna bolsista matriculada no curso de Licenciatura em Matemática, respectivamente, primeiro e segundo autor deste texto. As atividades foram desenvolvidas em duas turmas de Educação Infantil, denominadas como Fase I, para alunos de 4 anos e Fase II, para os de 5 anos. Compondo um total de 29 alunos.

Entretanto, durante o evento, a apresentação do trabalho submetido e a participação nos grupos de discussão, fizeram ampliar um pouco mais a compreensão sobre insubordinação criativa e, a partir disso, ficou o entendimento de que a trajetória profissional, do primeiro autor como professor de Educação Infantil, foi marcada pela subversão responsável o que culminou em muitos atos de insubordinação criativa, conforme destacam Lopes, D'Ambrosio e Corrêa (2016).

[...] cada professor é único, e define suas práticas com base em traços de personalidade, sentimentos, crenças e expectativas. Quando movidos para melhorar a aprendizagem dos alunos e investir na melhoria das condições em que essa aprendizagem ocorre, os professores criam e colocam padrões de movimento e procedimentos que estão alinhados com a sua identidade profissional. Essas atitudes são de forma responsavelmente subversiva e resultam em atos de insubordinação criativa. (LOPES; D'AMBROSIO; CORRÊA, 2016, p. 288)

Diante disso, pensando na trajetória, cabe aqui ressaltar que de acordo com Souza (2013), sendo ela entendida como um processo de construção, um movimento que leva à formação, ainda que inconclusa (FREIRE, 1996), inicia-se muito antes que seja dada conta de sua existência. A formação do professor começa, segundo Nacarato (2000), quando, ele ainda criança, entra em contato com a escolarização.

Os modelos de professores e de ensino vivenciados ao longo da vida escolar são muito marcantes e, por serem influências, serão copiados em diferentes momentos de sua atuação profissional e é possível afirmar que, os subversivos, tanto os professores quanto os modelos de ensino, são os mais marcantes. Durante sua trajetória, o professor constrói e reconstrói seus conhecimentos conforme sua necessidade, bem como suas experiências, seus percursos formativos e profissionais (NUNES, 2001).

Para melhor compressão da produção do presente trabalho é fundamental que se conheça a trajetória do professor da licenciatura e o cruzamento de sua trajetória com a da licencianda. Inicialmente há uma narrativa na primeira pessoa do singular, pois se refere à trajetória do professor pesquisador. Em um dado momento essa trajetória irá se cruzar com a de sua orientanda que, mesmo estando num curso de formação de 
professores de Matemática, ousou trabalhar com Educação Estatística na Educação Infantil. A partir daí, o texto é tecido na primeira pessoa do plural.

\section{Os primeiros atos de insubordinação criativa}

Certa vez, recebi de um amigo uma mensagem (de autoria desconhecida), contando uma história sobre uma equipe de cientistas que fez um experimento com um bando de macacos. Em tal experimento, os macacos foram colocados em uma sala, onde havia uma escada e sobre ela um cacho de bananas. Toda vez que algum deles subia para pegar uma banana, os demais recebiam uma ducha de água gelada. Depois de algumas vezes que isso acontecia, os que recebiam a ducha batiam naquele que tentava subir e com isso, nenhum macaco tentou subir a escada novamente.

Os cientistas então retiraram um dos macacos do bando, o substituindo por outro. O novo membro, ao ver as bananas sobre a escada, logo tratou de subir e prontamente recebeu, de seus companheiros que tinham tomado banhos de água gelada em episódios anteriores, a punição por seu ato, o que se repetiu em outras de suas tentativas, mesmo não havendo mais a ducha de água gelada sobre seus agressores, até que ele não insistiu mais. Com isso, novamente os cientistas fizeram uma substituição e o mais novo membro também apanhou em todas as vezes que tentou subir na escada. Assim o estudo prosseguiu até que todos os macacos que iniciaram o experimento foram substituídos e nenhum dos macacos do segundo bando tomou a ducha gelada quando um companheiro tentava subir. $O$ que se observou foi que os espancamentos continuavam sempre que um novo membro tentava subir a escada. Os macacos espancadores não sabiam por que batiam, pois não tinham, em momento algum, tomado a ducha de água gelada.

A história contada na mensagem me fez pensar no quanto, muitas vezes, fazemos algo sem questionar e não somos tomados pelo estranhamento ao nos depararmos com determinadas situações. Na maioria das vezes a justificativa é que "quando cheguei aqui já era desse jeito" ou "sempre foi assim". O que me levou a fazer uma relação com o início de minha carreira como professor de Educação Infantil.

Quando iniciei havia concluído o curso de Magistério há pouco menos de dois anos. Esta formação me habilitava para lecionar para a Educação Infantil e para os primeiros anos do Ensino Fundamental. Nessa época ainda não percebia a necessidade de um ensino de Matemática que fosse adequado à Educação Infantil e que atendesse as necessidades dos alunos para os quais eu lecionava. A ausência de percepção talvez tenha ocorrido por falta de conhecimento, já que, no curso de Magistério, fora dada pouca ênfase a essa disciplina e, o curso de Licenciatura em Matemática, que iniciei pouco tempo depois, não tinha como objetivo a formação para atuar com as crianças.

No ambiente que encontrei não se imaginava a possibilidade de ensinar Matemática na Educação Infantil e muito menos que os alunos dessa idade pudessem aprendê-la. As concepções vigentes na época sobre o quê ou como seria uma aula de Matemática, tanto no Magistério, quanto na universidade, impediam as possibilidades de se pensar em um ensino efetivo de Matemática para alunos da Educação Infantil. De certo, tais concepções iam ao encontro do que diz Megid (2015) quando afirma que as aulas de Matemática evocam, em nosso imaginário, momentos de exposição dos 
professores e de repetição de procedimentos dos alunos na execução das atividades. Entretanto, como um macaco recém-chegado ao bando, tentei, ainda que de forma tímida e sem uma intencionalidade clara, subir alguns degraus para pegar algumas bananas.

No início de minha carreira na Educação Infantil, minhas referências para o trabalho com as crianças eram minhas colegas "antigas na rede", como se autodenominavam. Refiro-me no feminino porque fui o primeiro professor do sexo masculino a ingressar naquela rede municipal. Éramos então cerca de duzentos profissionais e, de certa forma, minha presença causou estranhamento em muita gente. Por outro lado, em pouco tempo, meu estranhamento surgiu diante da forma de trabalho e os objetivos ali vigentes para o trabalho com as crianças.

A rede demonstrava uma grande preocupação quanto à preparação do aluno para a alfabetização e para o primeiro ano do Ensino Fundamental. Para tanto era feito um trabalho centrado, principalmente, na aprendizagem das letras do alfabeto, dos algarismos de um a dez, de escrita (cópia) de palavras em letra bastão e cursiva.

Com o término do curso de graduação, ao ingressar em um curso de extensão universitária no Instituto de Matemática e Estatística da Universidade de São Paulo (IMEUSP), tomei conhecimento da existência do Centro de Aperfeiçoamento do Ensino de Matemática (CAEM). O que o CAEM oferecia era bem mais interessante e útil, para o momento profissional que eu vivia, do que era proposto no curso de extensão, o que me levou a participar de algumas oficinas e minicursos. No mesmo ano, participei de um encontro de professores de Matemática. Ali tive meu primeiro contato com os trabalhos dos Professores Doutores Ubiratan D’Ambrósio, Anna Regina Lanner de Moura e Manoel Oriosvaldo de Moura. O que vi de seus trabalhos e minhas participações nas atividades do CAEM me fizeram refletir muito sobre minha atuação como professor, contribuindo para a melhoria de minha formação inicial e prática profissional. Tudo que vi e aprendi me despertou a curiosidade e o senso crítico no que se refere ao ensino de Matemática, principalmente para a Educação Infantil. E aí, por que não pegar mais algumas bananas?

A partir disso, por muitas vezes me sentia incomodado com a maneira como era tratado o ensino de Matemática para as crianças. Em cursos de capacitação oferecidos pela rede e discussões com os colegas não percebia uma preocupação com o ensino de Matemática. Falava-se e ouvia-se muito sobre alfabetização, enquanto a Matemática se resumia a contagem de 1 a 10, o reconhecimento dos respectivos algarismos e o reconhecimento de formas geométricas planas (quadrado, círculo e triângulo). Porém, mesmo o que era proposto como alfabetização não surtia o efeito que se tinha como objetivo, pois se caracterizava por exercícios repetitivos para aprimorar a coordenação motora manual, além de cópia de letras e palavras. Penso que para uma criança ser alfabetizada, ela precisa não só de uma de suas mãos, mas de sim de todo seu corpo. É preciso ampliar seu repertório, sua percepção sobre si e sobre as coisas que a cerca. $E$ também, porque não dizer, a alfabetização não se limita a desenhar e decifrar símbolos da Língua Portuguesa, vai muito além disso.

Com a publicação do Referencial Curricular Nacional para Educação Infantil RCNEI - (BRASIL, 1998), iniciaram-se na rede, novas discussões sobre o ensino na 
Educação Infantil. Foram propostos estudos do RCNEl e novos cursos de formação, entretanto, as discussões sobre a Matemática eram precárias ou inexistentes.

Nessa ocasião, meu contato com a coordenação geral de educação da rede municipal era frequente, o que me permitia questionar e discutir sobre a necessidade de pensar em um ensino de Matemática, para as crianças, que fosse além do que fora citado neste texto. Sempre questionava o porquê de não haver cursos de formação voltados à Matemática. Em uma dessas discussões, fui convidado a ministrar oficinas pedagógicas de Matemática para os professores da rede.

Assim, por três anos seguidos, ministrei oficinas a professores de Educação Infantil e do Ensino Fundamental. O conteúdo tratado nas oficinas era resultante do que eu tinha aprendido nas atividades do CAEM, de minhas experiências de sala de aula, de minhas leituras e reflexões.

No período em que atuei na Educação Infantil utilizei muito a literatura infantil em minhas aulas de Matemática, fruto do que aprendi no CAEM. O uso dessa literatura se deu, principalmente, por se tratar de algo que se configura como uma das situações possíveis para contextualização nas aulas de Matemática, e como nos relata Coelho (2000), este tipo de literatura é uma arte, um fenômeno de criatividade que representa o mundo, o homem, a vida, através da palavra e funde os sonhos e a vida prática e o real, os ideais e sua possível/impossível realização.

Ao se verificar os propósitos para literatura infantil, Coelho (2000), nos apresenta dois propósitos, sendo eles:

- Como entretenimento (a arte literária): é um objeto que provoca emoções, dá prazer ou diverte e modifica a consciência do mundo de seu leitor.

- Na área pedagógica: serve como instrumento manipulado por uma intenção educativa.

Assim, ao se pensar na utilização da literatura infantil nas aulas de Matemática, é importante ter em mente que o foco inicial não é a Matemática, pois ainda embasado Coelho (2000), a literatura infantil é, antes de tudo, literatura. Dessa forma, no início do trabalho o foco é o entretenimento. É preciso então, que a história seja mais de uma vez, que os alunos a vivenciem e façam suas interpretações. Amarilha (1997), afirma que o receptor de uma história, no caso a criança, envolve-se em eventos diferentes daqueles que está vivendo na vida real e, através desse envolvimento intelectual, emocional e imaginativo, experimenta fatos, sentimentos, reações de prazer ou frustração.

Neuenfeldt (2006) afirma que as histórias não são formadas de pura fantasia, e que sempre haverá a possibilidade de estabelecermos pontes entre a história e a realidade. Algumas vezes, à sua maneira, as próprias crianças estabelecem essas pontes e, entendo que são por meio delas que o professor cria o contexto e estabelece a relação entre a história contada e as ideias matemáticas as quais se quer abordar. Em outras palavras, o professor faz uso do propósito pedagógico da literatura, conforme definido por Coelho (2000).

Entretanto, para que seja possível o uso da literatura infantil em seu propósito pedagógico, seja nas aulas de Matemática ou em outras situações, é preciso, antes de 
tudo que haja intencionalidade (ANDRADE, 2007). Como afirma Souza (2013), a intencionalidade dá ao professor condições para refletir sobre seu trabalho e lhe propicia melhores condições para estabelecer relações e para intervir em sua prática.

Como consequência do trabalho realizado em sala de aula, veio a pesquisa. No mestrado, a escolha do tema de pesquisa surgiu quando apresentei algumas atividades, sobre construção e leitura de gráficos e tabelas estatísticos, à Professora Doutora Celi Lopes, que na ocasião, ministrava uma das disciplinas do curso.

As atividades apresentadas foram desenvolvidas com meus alunos da época e a ideia de trabalhar o tema surgiu após o questionamento de um aluno ao encontrar um gráfico de linhas em uma folha de jornal. Seu questionamento me levou a refletir sobre a importância de iniciar, o quanto antes, um trabalho visando ao desenvolvimento da capacidade de leitura e de interpretação de gráficos e tabelas, ainda que se tratasse de alunos não alfabetizados.

As interpretações baseadas em um grupo de informações, em representações de dados e em sínteses estatísticas de dados são, segundo Garfield e Gal (1999), características do raciocínio estatístico. Daí a importância da comunicação de ideias a partir de tabelas e gráficos, pois se trata de uma forma de iniciar o desenvolvimento do raciocínio estatístico das crianças. Dessa forma, concordando com D’Ambrosio e Lopes (2015) quando afirmam que a criação e a ousadia presentes na ação docente, são decorrentes do desejo de promover uma aprendizagem na qual os estudantes atribuam significados ao conhecimento, seja ele de qualquer natureza.

A pesquisa de mestrado (SOUZA, 2007), foi desenvolvida com meus alunos que tinham entre 5 e 6 anos e ainda eram alunos não leitores. $O$ trabalho teve como ponto de partida minha inquietação no que se refere ao ensino e à aprendizagem da Matemática e da Estatística na Educação Infantil. A proposta para a pesquisa com as crianças contemplava etapas referentes a uma investigação estatística, sendo elas:

- Escolha de um tema para pesquisa.

- Elaboração de instrumentos para coleta de dados.

- Coleta de dados.

- Tabulação dos dados.

- Representação dos dados.

- Interpretação.

- Conclusão.

- Comunicação dos resultados.

O conhecimento profissional adquirido com a pesquisa de mestrado fez surgir a necessidade de divulgar e compartilhar o trabalho realizado além da escola e da rede de ensino em que eu atuava, assim comecei a participar regularmente de eventos da área de Educação Matemática sempre propondo alguma atividade a ser desenvolvida (minicurso; comunicação; palestra) e participando de espaços de debate. 
Como consequência das experiências de sala de aula e da pesquisa de mestrado, ingressei no curso de doutorado para desenvolver um trabalho, que contou com a participação de um grupo formado por seis professoras, sendo cinco de Educação Infantil e uma professora do primeiro ano do Ensino Fundamental e visou investigar, entre outros aspectos, como se pode suscitar uma formação continuada referente à Educação Estatística e provocar um processo de reflexão sobre a prática docente do educador da Infância quando promove a aprendizagem matemática e estatística. Além de apresentar algumas contribuições à investigação da prática e à formação das professoras, bem como ao processo de desenvolvimento de pensamentos e raciocínios relacionados à Educação Estatística na Escola Básica.

Minha atuação como professor de Educação Infantil durou 15 anos. Foi interrompida quando ingressei no doutorado, em um momento que tive que fazer a escolha sobre qual de minhas atividades me afastaria, porém, entendia que minha relação com esta etapa da Educação Básica não chegaria ao fim. A formação adquirida na graduação, no mestrado e no doutorado me proporcionou atuar como professor no curso de Licenciatura em Matemática. Contudo, isso não me impediu de desenvolver projetos para e com as crianças e novamente, como um dos macacos, me vi diante de uma escada para pegar bananas.

\section{E os atos continuaram: trajetórias que se cruzam}

É interessante pensar que os próprios documentos oficiais que tratam da educação das crianças, favorecem com o surgimento de atos de insubordinação criativa. O RCNEI (BRASIL, 1998) não apresenta em seu texto referências para a abordagem de ideias relacionadas à Estatística e um documento mais recente, as Diretrizes Curriculares para a Educação Infantil (BRASIL, 2010) também não o faz. Entretanto, neste último, há um trecho que faz menção à ampliação, no desenvolvimento da criança, de saberes e conhecimentos de diferentes naturezas.

Pensando nisso, por que não pegar uma banana? Que aqui entendemos como: por que não abordar ideias relacionadas à Estatística com as crianças? Os conteúdos relacionados à Estatística, assim como os relacionados à Combinatória e à Probabilidade foram introduzidos nos currículos de Matemática da Escola Básica, no Brasil, a partir dos anos 1990 (COSTA e NACARATO, 2011) e com maior ênfase após a publicação dos Parâmetros Curriculares Nacionais (BRASIL, 1997). Segundo as autoras, tal inserção ocorreu de forma tardia em comparação com outros países e sem que houvesse formação prévia dos professores para trabalhar com essa temática na Escola Básica.

Não há como desconsiderar que o professor precisa ter um repertório de saberes (PONTE, 1992) para desenvolver adequadamente seu trabalho em sala de aula. Se o professor não passa por experiências significativas durante sua escolarização e formação inicial, é provável que se sinta inseguro para incorporá-la em sua prática profissional (COSTA e NACARATO, 2011). O professor precisa sentir-se protagonista daquilo que prepara para a sua sala de aula e não um mero aplicador de atividades elaboradas por alguém de fora dela. 
Pensando nisso, o entendimento de que o aluno do curso de graduação em Matemática precisa passar por situações que the proporcione as tais experiências significativas fez surgir a ideia de envolver uma aluna, graduanda em Matemática, em um projeto que abordasse ideias matemáticas e estatísticas com as crianças. De início, a proposta do projeto era envolver, além de graduandos em Matemática, também graduandos em Pedagogia e professores que ensinam Matemática em diferentes etapas da Educação Básica, entretanto, foi necessário fazer algumas adequações e com isso houve a participação de somente uma aluna.

A aluna bolsista, segunda autora deste texto, cursou a Educação Básica em escola pública e como bolsista do Programa Núcleos de Ensino da Universidade Estadual Paulista, iniciou sua participação no projeto em seu primeiro ano de graduação. Suas inquietações quanto ao ensino de Matemática surgiram quando ainda era aluna da Educação Básica, sendo esse um dos fatores que contribuíram para a escolha do curso de Licenciatura em Matemática. Já o interesse em participar do projeto surgiu, após nossas primeiras conversas, pela curiosidade sobre como seria abordar ideias relacionadas à Matemática e à Estatística com crianças pequenas.

No projeto, além do trabalho com os alunos na escola parceira, outra preocupação foi em discutir com a aluna bolsista, questões relacionadas à Educação Infantil, considerando que esta seria sua primeira experiência com as crianças e também foi preciso considerar momentos de estudos e discussões relacionadas à Estatística, mais precisamente à Educação Estatística. Dessa forma, sua participação em um projeto desse tipo, tendo em vista o que se propõe a formação que está recebendo em seu o curso de graduação, pode ser como entendido mais um ato de insubordinação criativa.

Pamplona e Carvalho (2011) afirmam que a aprendizagem é o que muda nossa capacidade de compreensão, ela traz o entendimento de porque fazemos e quais são os recursos que temos à nossa disposição para fazê-lo. Assim, antes de iniciarmos o trabalho com as crianças, tivemos momentos de formação em que foram realizadas leituras de documentos oficiais elaborados para a Educação Infantil, leituras e discussões sobre trabalhos que tinham com foco a Matemática para as crianças, bem como leituras de trabalhos relacionados à Estatística. Como a proposta de trabalho do projeto também envolvia a literatura infantil foram realizadas leituras e discussões de alguns livros desse tipo de literatura.

\section{Um pouco do projeto}

Para o desenvolvimento das atividades com as crianças da escola parceira foram realizadas nove visitas e para este texto, a opção foi apresentar duas das atividades desenvolvidas, sendo a primeira com os alunos da Fase I, que teve como contexto a história do livro "Sabe de quem era aquele rabinho?" (SALLUT, 2008), e, a segunda, para os alunos da Fase II, com a história do livro "Centopeias e seus sapatinhos" (CAMARGO, 2000).

\section{A atividade para os alunos da Fase I: O dono do rabinho}

Ao elaborar qualquer atividade para as crianças da Educação Infantil, deve-se levar em consideração contextos que sejam relevantes para elas. Dessa forma, é importante 
destacar a percepção do professor na escolha do tema em suas respectivas atividades. Além disso, de acordo com Cazorla e Utsumi (2010), a escolha do tema para abordar ideias estatísticas é um aspecto crucial. Segundo as autoras, o tema possibilita a contextualização do problema a ser investigado, permite que a abordagem faça sentido para o estudante e propicia uma postura investigativa.

Em geral, a construção ou a mobilização de conhecimentos do professor, na abordagem de ideias matemáticas e estatísticas, só acontece quando o tema escolhido Ihe proporciona segurança. Assim, a sugestão é que os temas e os recursos didáticopedagógicos a serem utilizados no desenvolvimento das atividades sejam baseados nos contextos de sala de aula como as brincadeiras, os jogos, as histórias e outros.

No livro escolhido para a Fase I, a autora (SALLUT, 2008) conta a história de um elefante que irá fazer uma viagem e, por esse motivo, resolve fazer uma festa para se despedir dos amigos. Durante a festa, ele resolve tirar uma fotografia dos amigos para levar de recordação em sua viagem. Tira a foto, e depois um dos convidados sugere que todos fiquem de costas para a foto seguinte. Quando vai tirar a segunda foto, o elefante percebe que, no meio de todos, há um rabinho desconhecido.

A sequência de atividades proposta iniciou-se com o conto da história, feita sem que fosse mostrado o seu final, mantendo o mistério sobre quem é o dono do rabinho. Em geral as crianças em faixa etária, como as da Fase I, não estão alfabetizadas. Dessa forma, o conto e a compreensão da história são facilitados se as imagens do livro forem ampliadas e apresentadas a elas. Para tanto, o livro foi digitalizado e projetado com projetor multimídia. Porém, é muito importante que as crianças tenham o contato com o livro. Seu manuseio com explorações individuais ou em duplas é muito enriquecedor e contribui, entre outras coisas, para que a criança desenvolva o gosto pela leitura.

Depois da leitura da história e discussões, foi proposto que as crianças respondessem a uma pergunta sobre quem elas acreditavam ser o dono do rabinho desconhecido. As respostas dadas foram jacaré, urso, saci, esquilo, gato e zebra. Um fato, que chamou atenção, foi que dois nomes sugeridos, como possíveis donos do rabinho, foram gato e saci. Entretanto esses bichos (as crianças consideraram o saci como sendo um bicho), não estavam presentes na festa do elefante.

A representação e a apresentação dos dados foram feitas por meio de um gráfico de colunas, que, além de apresentar dados, também é uma forma de registro. Por se tratar de crianças pequenas, foi proposta a confecção coletiva, em um formato grande e que depois foi fixado em uma das paredes da sala de aula. No caso em questão, a variável (parte principal da pergunta: o dono do rabinho) é qualitativa, ou seja, as respostas possíveis (valores) são nomes (exemplo: urso, jacaré e zebra) e não números.

Para a confecção do gráfico, foi distribuído para as crianças pedaços de papel dobradura recortados em forma de retângulo, medindo $5 \mathrm{~cm}$ de altura por $8 \mathrm{~cm}$ de comprimento. As cores dos papéis eram correspondentes ao "voto", assim chamada a escolha da criança para o dono do rabo. Sendo azul para jacaré, amarelo para urso, marrom para saci, verde para esquilo, preto para gato e vermelho para zebra. Cada coluna do gráfico foi composta pela justaposição de retângulos de mesma cor. A escolha por esse tipo de gráfico se deve ao fato de ser este um tipo de gráfico que se adapta 
melhor às variáveis qualitativas (MAGALHÃES; LIMA, 2005), e por ser o mais adequado para o trabalho com estudantes dessa faixa etária (SOUZA, 2007).

Finalizada a confecção do gráfico, foi apresentado o final da história. A preocupação de algumas crianças era em saber quem tinha respondido corretamente à questão apresentada. Entretanto, o objetivo não era saber quem apresentaria a resposta correta e sim que as crianças pudessem discutir e estabelecer relações.

Foi observado que a quantidade de valores, atribuída pelas crianças, para a variável estudada (nome do dono do rabinho) dificultou a compreensão do gráfico e foi também observado que nem todos da turma dominavam noções de quantidade.

\section{A atividade para os alunos da Fase II: O número do calçado}

As atividades propostas tiveram por objetivo abordar ideias matemáticas e estatísticas a partir da leitura e das discussões sobre o livro "As Centopeias e seus sapatinhos" (CAMARGO, 2000), que trata da história de duas centopeias, mãe e filha, que, em um belo dia de sol, vão à sapataria da Dona Joaninha comprar sapatos. Para o conto da história, também houve a digitalização do livro e o uso da projeção.

Retomando a Neuenfeldt (2006), quando afirma sobre a possibilidade de se estabelecer pontes entre a história e a realidade, buscou-se estabelecer uma conexão entre as situações vividas pelas centopeias, ao comprarem seus sapatos, e a necessidade de um parâmetro, por parte das pessoas, para fazerem o mesmo, no caso, o conhecimento da existência da numeração dos calçados e seu uso.

Quando a atividade foi elaborada, foi levada em consideração a possibilidade de que as crianças da Fase II já tivessem noção da existência de um número em seu calçado, isso decorrente principalmente do convívio com pais e familiares. Além disso, também foi levado em consideração que elas também já tinham alguma noção da existência de uma relação entre o tamanho do pé e o número de um calçado.

De acordo com Castro e Rodrigues (2008), desde muito cedo as crianças se mostram capazes de distinguir números, seja para efetuarem contagens ou em outras situações de seu dia a dia, como identificar o número de sua casa ou de um telefone. De acordo com Cebola (2002), se pensarmos o número como aquilo que nos permite contar, medir e fazer cálculos, estamos considerando tal número como cardinal. No entanto, o número pode ser usado num sentido diferente - por exemplo, no sentido ordinal. Isso acontece quando se quer ordenar ou localizar um elemento qualquer entre outros dispostos numa ordem, como, por exemplo, falar da terceira ou da quarta pessoa em uma fila. Já os números, como o de telefone, número da casa ou do documento de identidade, são números utilizados para identificação, o que faz surgir o conceito de nominal. Neste conceito, a função do número é nomear.

O número de um calçado é resultante de uma medida realizada a partir de uma unidade chamada "ponto". Para a fabricação dos calçados no Brasil, considera-se um ponto como o equivalente a 0,666 centímetros. Assim, uma pessoa cujo pé mede aproximadamente 26 centímetros usará um calçado de 39 pontos, ou seja, um calçado de número 39. Dessa forma, de acordo com o que define Cebola (2002), o número do calçado é um número cardinal. Entretanto, como o ponto é uma unidade de medida pouco 
ou nada conhecida para a maioria das pessoas e é quase certo que os alunos da Fase II ainda não possuíam conhecimentos sobre medida, o trabalho foi realizado considerando o número do calçado como um número nominal, ou seja, com a função de identificação.

Após a leitura do livro, foram propostos alguns questionamentos para gerar uma discussão com as crianças, entre eles se alguém da turma já havia acompanhado um adulto em uma compra de calçados e como o vendedor pode saber se vendeu para a pessoa o calçado do tamanho certo.

Depois da discussão, cada criança recebeu uma folha de papel sulfite, na qual deveriam desenhar o contorno de seu calçado. Para que houvesse um padrão, todos foram orientados a fazer o contorno do calçado do pé direito. Em seguida, deviam procurar no calçado, o seu número. Intervenções foram necessárias para orientar as crianças onde procurar o número (na sola, na língua do calçado ou na palmilha). Com os contornos prontos e o registro dos respectivos números, foi proposto a cada um que procurasse por colegas de sua turma que calçavam o mesmo número que o seu e formasse um grupo.

Depois disso, as crianças foram convidadas a participar da construção coletiva de um gráfico de colunas. Para isso, foi colada uma fita adesiva no chão, abaixo da fita uma sequência de números, feita com giz, correspondente aos números dos calçados de cada grupo. Em seguida, cada criança colocou a folha com o contorno de seu calçado acima da fita na direção ao número de seu calçado. A justaposição das folhas que continham os mesmos números formaram as colunas do gráfico.

As discussões realizadas durante a atividade contribuíram para que os alunos iniciassem o processo de estabelecer relações entre o tamanho de seu pé e o número de seu calçado, o que poderá permitir, futuramente, a compreensão de tal número em seu conceito cardinal.

\section{Algumas considerações}

Em ambientes destinados à Educação Infantil não é pouco comum encontramos práticas da sala de aula que não atendem às necessidades das crianças. Entendemos que proporcionar, a um grupo de crianças, situações que contribuam para 0 desenvolvimento de seus saberes e conhecimentos de diferentes naturezas, em um ambiente que não tem isso como uma prática constante, seja um ato de insubordinação criativa. A criança, ao contrário do que ainda muita gente tem em mente, é um ser pensante que tem suas opiniões, vontades e necessidade. Nunca deve ser subestimada e acima de tudo, deve ser tratada com respeito.

No projeto foi possível perceber que a participação das crianças, a princípio, foi um pouco tímida, e aos poucos, à medida que as relações de confiança eram construídas, foi se tornando cada vez mais intensa. Pesquisas como as de Lopes (2003) e Souza (2007) apontam para as potencialidades de se trabalhar noções de Estatística desde a Educação Infantil. Entretanto, é preciso que mais trabalhos relacionados à Educação Matemática e à Educação Estatística cheguem às escolas. Também é preciso que os professores deste nível de ensino sejam incentivados a inovar e a realizar eles mesmos suas próprias pesquisas. Entretanto, não é tarefa muito fácil para integrantes da universidade "entrar" na 
escola e propor situações diferentes das práticas ali existentes. A desconfiança é a maior barreira e estabelecer laços de confiança talvez seja o maior desafio e só depois disso é que se pode pensar no desenvolvimento da proposta propriamente dita.

Ao longo de nossas trajetórias, assim com um macaco ousado, teremos (assim como já tivemos) problemas ao tentar pegar uma banana. Foi e será preciso muitas vezes, nos valendo de argumentações, convencer colegas de que certas decisões e opções escolhidas podem surtir mais efeito do que aquelas que já prescritas. Em todos os casos, o sucesso só é possível se, conforme afirma Abreu (2003), entendermos que argumentar não se trata de provar o tempo todo que se tem razão e impor vontades. Argumentar é, segundo o autor, convencer no sentido de vencer junto com o outro com ética, ouvindo e entendendo suas necessidades e emoções, dessa forma removendo os obstáculos que impedem o consenso.

\section{Referências}

ABREU, A. S. A arte de argumentar: gerenciando razão e emoção. 6ª Edição. Cotia: Ateliê Editorial, 2003.

ANDRADE, D. O. Contando histórias: produção/mobilização de conceitos na perspectiva da resolução de problemas em matemática. Dissertação (Mestrado em Educação). Universidade São Francisco, Itatiba. 2007.

BRASIL. Secretaria de Educação Fundamental. Parâmetros curriculares nacionais: matemática. Secretaria de Educação Fundamental. Brasília: MEC/SEF, 1997.

BRASIL. Ministério da Educação e do Desporto. Secretaria Fundamental de Educação. Referencial curricular nacional para a educação infantil. Brasília: MEC/SEF, 1998.

BRASIL. Ministério da Educação. Secretaria de Educação Básica. Diretrizes curriculares nacionais para a educação infantil. Brasília: MEC, SEB, 2010.

CASTRO, J. P.; RODRIGUES, M. Sentido de número e organização de dados: textos de apoio para educadores de Infância. Lisboa: Ministério da Educação, 2008.

CAZORLA, I. M.; UTSUMI, M. C. Reflexões sobre o ensino de Estatística na Educação Básica. In: CAZORLA, I. M.; SANTANA, E. (Org.). Do tratamento da informação ao letramento estatístico. Itabuna: Via Literarum, 2010.

CEBOLA, G. Do número ao sentido do número. In: ENCONTRO DE INVESTIGAÇÃO EM EDUCAÇÃO MATEMÁTICA, 11, 2002, Coimbra, Actas... Coimbra, 2002. p. 223-239.

COELHO, N. N. Literatura Infantil: teoria, análise, didática. $7^{a}$ Edição. São Paulo: Moderna. 2000.

COSTA, A.; NACARATO, A. M. A Estocástica na Formação do Professor de Matemática: percepções de professores e de formadores. Bolema, Rio Claro, v. 24, n. 39, p. 367-386, ago. 2011.

D'AMBROSIO, B.; LOPES, C. E. Insubordinação Criativa: um convite à reinvenção do educador matemático. Bolema, Rio Claro, v. 29, n. 51. 2015. 
FREIRE, P. Pedagogia da autonomia: saberes necessários à prática educativa. São Paulo: Paz e Terra, 1996.

LOPES, C. E. O conhecimento profissional dos professores e suas relações com estatística e probabilidade na educação infantil. 2003. 290 f. Tese (Doutorado) Faculdade de Educação, Universidade Estadual de Campinas, Campinas, 2003.

LOPES C. E.; D'AMBROSIO, B. S.; CORRÊA, S. A. A Insubordinação Criativa em Educação Matemática Promove a Ética e a Solidariedade. Zetetiké, Campinas, SP, v.24, n.3, set./dez. 2016, p.287-300.

MAGALHÃES, M. N.; LIMA, A. C. P. Noções de probabilidade e estatística. São Paulo: Edusp, 2005.

MEGID, M. A. B. A. Insubordinação criativa consentida e esperada na formação de professores dos anos iniciais. In: D'AMBROSIO, B. S.; LOPES, C. E. (Org.). Ousadia criativa na prática de educadores matemáticos. Campinas: Mercado de Letras, 2015.

NACARATO, A. M. Educação continuada sob a perspectiva da pesquisa-ação: currículo em ação de um grupo de professoras ao aprender ensinando Geometria. Tese (Doutorado)-Universidade Estadual de Campinas. Faculdade de Educação. Campinas, 2000.

NEUENFELDT, A. E. Matemática e Literatura Infantil: sobre limites e possibilidades de um desenho curricular interdisciplinar. Dissertação (Mestrado em Educação). Universidade Federal de Santa Maria, Santa Maria. 2006.

NUNES, C. M. F. Saberes docentes e formação de professores: Um breve panorama da pesquisa brasileira. Educação \& Sociedade, ano XXII, n. 74, abr. 2001.

PAMPLONA, A. S.; CARVALHO, D. L. A Educação Estatística e as relações de poder em comunidades de prática. Bolema, Rio Claro, v. 24, n. 39, p. 351-366, ago. 2011.

PONTE, J. P. (Ed.). Educação matemática: temas de investigação. Lisboa: Instituto de Inovação Educacional, 1992. p. 185-239.

SOUZA, A. C. A Educação Estatística na Infância. Dissertação (Mestrado em Ensino de Ciências e Matemática). Universidade Cruzeiro do Sul, São Paulo. 2007.

SOUZA, A. C. O desenvolvimento profissional de Educadoras da Infância: uma aproximação à Educação Estatística. Tese (Doutorado em Ensino de Ciências e Matemática). Universidade Cruzeiro do Sul, São Paulo. 2013.

Submissão: 30/08/2017

Aceite: $28 / 11 / 2017$ 